\title{
Agro-morphological characterization of upland rice accessions
}

\author{
Wellington Ferreira do Nascimento ${ }^{1}$, Edson Ferreira da Silva ${ }^{2}$, Elizabeth Ann Veasey ${ }^{3 *}$ \\ ${ }^{-1}$ USP/ESALQ - Programa de Pós-Graduação em Genética e Melhoramento de Plantas, Piracicaba, SP - Brasil. \\ ${ }^{2}$ UFRPE - Depto. de Biologia, Av. Dom Manoel de Medeiros - 52171-900 - Recife, PE - Brasil. \\ ${ }^{3}$ USP/ESALQ - Depto. de Genética, C.P. 83 - 13400-970 - Piracicaba, SP - Brasil. \\ *Corresponding author <eaveasey@esalq.usp.br> \\ Edited By: Leonardo Oliveira Medici
}

\begin{abstract}
The agro-morphological characterization is fundamental in order to provide information for plant breeding programs. The aim of the present study was to characterize 146 accessions of upland rice (Oryza sativa L.), based on qualitative and quantitative agro-morphological descriptors. The experiment was conducted in Recife, state of Pernambuco, Brazil, using a randomized block design with three replicates. Polymorphism was observed among 12 of 14 qualitative characters evaluated, whereas significant differences $(p<0.05)$ were observed for 11 of the 14 analysed quantitative traits. Genetic variance was higher than environmental variance and the average inheritability coefficients were above $80 \%$ for all characters, which ensures the predominance of the genetic components in the differences observed among accessions. On the cluster analysis for qualitative traits the accessions were classified in two groups with a total of 18 duplicates, whereas for the quantitative traits three groups were obtained with few subgroups. The principal component analysis for quantitative traits showed great dispersion of the accessions. The most divergent group of accessions included the genotypes Mitsukasane, Mie, Tomoe mochi, Ooba kirishima and Nourin mochi 6, which showed a higher number of spicklets per plant. There is high variability among the rice accessions from the germplasm collection studied, which presents great importance for breeding programs or for genetic studies on this species.

Keywords: genetic variability, germplasm, ex-situ conservation, pre-breeding
\end{abstract}

\section{Introduction}

Agro-morphological characterization of germplasm accessions is fundamental in order to provide information for plant breeding programs (Lin, 1991). Several researchers reported the use of agro-morphological markers in the characterization and study of rice (Oryza sativa L.) germplasm diversity. Li et al. (2000) obtained consistent results analyzing the correlation between genetic and morphological differentiation in 111 accessions of rice from the Japonica and Indica groups. Yawen et al. (2003) studied the genetic diversity on 5285 accessions of indigenous rice in China and found considerable morphological variation among accessions. In India, Patra and Dhua (2003) analyzed the agro-morphological diversity of upland rice and in Vietnam, Fukuoka et al. (2006) assessed the variability in agronomic characters among landraces of aromatic rice populations. Using 42 agro-morphological characters associated with 39 SSR markers, Bajracharya et al. (2006) examined the genetic relationships among 147 high altitude rice landraces from Jumla, Nepal. Seetharam et al. (2009) characterized 30 rice genotypes comprising landraces, pure lines, somaclones, breeding lines and varieties specifically adapted to costal saline environments using SSR markers and morphological characters. Yibo et al. (2010) investigated morphological and genetic diversity in 11 surviving populations of O. rufipogon Griff. from Hainan Island, China, and reported a clear morphological differentiation among or within populations.

This type of characterization has also been used on wild species in Brazil. Rosa et al. (2006) characterized eight populations of $O$. glumaepatula Steud. collected in different hydrographic basins and Veasey et al. (2008) analyzed the genetic variability among the four wild rice species occurring in South America, reporting agro-morphological variation for $O$. glumaepatula, followed by $O$. latifolia.

The aim of the present study was to characterize 146 upland rice genotypes using agro-morphological characters and to provide useful information to facilitate the choice of genitors for rice plant breeding programs.

\section{Materials and Methods}

One hundred and forty-six accessions of upland rice were assessed in this study (Table 1). Three Brazilian cultivars were used as controls: IAC 202, IAC 47 and Bonança.

The experiment was carried out in Recife, state of Pernambuco in northeast Brazil, (08 $01^{\prime} \mathrm{S}$; 34 $34^{\circ}$ ' W - 10.3 m altitude), from March to July 2007, during the agricultural year in the region. The mean temperature during the experiment was $23.8^{\circ} \mathrm{C}$ and the index annual rainfall was $1.193 \mathrm{~mm}$.

Seeds were germinated in polystyrene trays with a substrate composed of Pinus husk, vermiculite, fine peat, macro and micronutrients. Twenty-eight days after emergence, the most vigorous seedlings of each genotype were transplanted to the field, following the procedure reported by Villela and Furlani Júnior (1996). The statistical experiment design was a randomized block with three replicates. Each plot consisted of a row of six plants spaced $0.15 \mathrm{~m}$ apart, with the rows spaced $0.40 \mathrm{~m}$ apart.

The accessions were characterizated according to descriptors established by the International Rice Research Institute and the International Board for Plant Genetic Resources (IRRI, 1980). A total of 14 qualitative (Table 2) and 14 quantitative descriptors (Table 3) were used. The qualitative descriptors were: leaf color (LC), leaf pubescence (LP), lodging resistance (LR), internode

Sci. Agric. (Piracicaba, Braz.), v.68, n.6, p.652-660, November/December 2011 
Table 1 - List of accessions of upland rice from Japan from the germplasm collection of Universidade Federal Rural de Pernambuco - UFRPE and the Brazilian cultivars (controls) studied.

\begin{tabular}{|c|c|c|c|c|c|c|c|c|c|c|c|}
\hline $\mathrm{N}^{\mathrm{o}}$ & Acc. & Genotype & $\mathrm{N}^{\circ}$ & Acc. & Genotype & $\mathrm{N}^{\circ}$ & Acc. & Genotype & $\mathrm{N}^{\circ}$ & Acc. & Genotype \\
\hline 1 & 1 & Kunihikari mochi & 39 & 144 & Miyamae okute & 77 & 261 & Kahei & 115 & 337 & (337) \\
\hline 2 & 2 & Senshou & 40 & 153 & Col/Fukuti/1965* & 78 & 263 & Tamasari 3 & 116 & 339 & Owari 79 \\
\hline 3 & 3 & Fukuton & 41 & 156 & Tachiminori & 79 & 264 & Miyakonojoo mochi & 117 & 343 & Tamasari mochi \\
\hline 4 & 8 & Shin hakaburi & 42 & 159 & Minami hata mochi & 80 & 268 & Ookuma nishiki & 118 & 352 & Rikuu 15 \\
\hline 5 & 12 & Senshou ibaragi 1 & 43 & 164 & No mochi & 81 & 269 & Nourin mochi 6 & 119 & 355 & Col/ Miyazaki/1963* \\
\hline 6 & 16 & Namekata mochi & 44 & 171 & Oosumi & 82 & 271 & Taishou nishiki & 120 & 357 & Rikuu 22 \\
\hline 7 & 23 & Sonobe mochi & 45 & 172 & Oohataho & 83 & 273 & Shina mochi & 121 & 364 & Fujimizu bansei \\
\hline 8 & 25 & Seion uruchi & 46 & 173 & Nourin 11 & 84 & 274 & Nagae wase & 122 & 365 & Iwate kinsen 1 \\
\hline 9 & 27 & Gaisen mochi & 47 & 175 & Tomoe mochi & 85 & 276 & Arabiya mochi & 123 & 367 & Bansei tarou \\
\hline 10 & 29 & Shiro hige & 48 & 177 & Nourin 16 & 86 & 277 & Tozo mochi & 124 & 368 & Shiro uzura \\
\hline 11 & 36 & Nakaahara mochi & 49 & 183 & Yashino mochi & 87 & 278 & Urasar & 125 & 369 & (369) \\
\hline 12 & 38 & Nourin mochi* & 50 & 184 & Akayakan & 88 & 279 & Ootama & 126 & 370 & $(370)$ \\
\hline 13 & 41 & Iwata hata mochi & 51 & 186 & Kirishima* & 89 & 280 & Okabo mochi & 127 & 373 & Mogami uruchi 1 \\
\hline 14 & 44 & Hassaku mochi & 52 & 189 & Okabo & 90 & 284 & Furuwase & 128 & 374 & Gaisen* \\
\hline 15 & 45 & Mitsukasane & 53 & 191 & Col/Fukuti/1965* & 91 & 285 & Hirakawa okute & 129 & 378 & Okka modoshi \\
\hline 16 & 48 & Mie & 54 & 199 & Kahee & 92 & 286 & Nourin 7 & 130 & 379 & Mino senshutsu \\
\hline 17 & 50 & Wase esoshima mochi & 55 & 200 & Hitachi nishiki & 93 & 287 & Oiran & 131 & 380 & Rikutou \\
\hline 18 & 52 & Mizuhoshi & 56 & 202 & Ooba kirishima & 94 & 289 & Shinhoku daiou mochi & 132 & 382 & Kurohige \\
\hline 19 & 55 & Oohata mochi & 57 & 203 & Horarin & 95 & 290 & Riku araki & 133 & 383 & Mogami chikanari 1 \\
\hline 20 & 56 & Miyako & 58 & 206 & Taishou mochi & 96 & 293 & Suzume shirazu & 134 & 384 & Kounoso rikutou 2 \\
\hline 21 & 57 & Yoridashi & 59 & 214 & Kaneko mochi & 97 & 294 & Col/Miyazaki/1963* & 135 & 386 & Minami hata mochi \\
\hline 22 & 69 & Saitama senshou & 60 & 216 & Iwate kurumi wase 1 & 98 & 295 & Hideshirazu mochi & 136 & 387 & Wase shinshuu \\
\hline 23 & 70 & Kirishima* & 61 & 217 & Col/Miyazaki/1963* & 99 & 299 & $(299)$ & 137 & 389 & Igisu mochi \\
\hline 24 & 74 & Aichi rikutou 1 & 62 & 218 & Toukyo haneko & 100 & 302 & Kazusa wase & 138 & 394 & Susono mochi \\
\hline 25 & 78 & Yonoyuki mochi & 63 & 219 & Gaisen $(4 x)^{*}$ & 101 & 304 & Shinkuko mochi & 139 & 395 & Seta gaisen \\
\hline 26 & 79 & Dango mochi & 64 & 228 & Tariu saku mochi & 102 & 308 & Hikouki gome & 140 & 397 & Korotou mochi \\
\hline 27 & 80 & Sangoku & 65 & 229 & Col/Tokushima/1967* & 103 & 310 & Senshou* & 141 & 401 & Ishiyakushi mochi \\
\hline 28 & 82 & Terenzu & 66 & 230 & Miyanishiki & 104 & 312 & Col/Ooita/1964 & 142 & 402 & Shiro hige \\
\hline 29 & 99 & Eika ine & 67 & 235 & Hatamurasaki & 105 & 314 & Taiwan mochi & 143 & 407 & Edogawa \\
\hline 30 & 127 & Hakamuri 20 & 68 & 236 & Toga & 106 & 315 & Urasan & 144 & 408 & Gose yonkoku \\
\hline 31 & 129 & Esojima mochi & 69 & 239 & Col/Miyazaki/1963* & 107 & 317 & Owari mochi & 145 & 410 & Shizouka \\
\hline 32 & 130 & Esojima & 70 & 248 & Col/Tokushima/1967* & 108 & 320 & Nourin mochi 2 & 146 & 413 & Chousen \\
\hline 33 & 131 & Mino & 71 & 250 & Jouon & 109 & 322 & Senshou* & 147 & 420 & IAC $202^{* *}$ \\
\hline 34 & 133 & Nourin mochi* & 72 & 252 & Oota wase & 110 & 325 & Gaisen mochi 909 & 148 & 421 & IAC $47 * *$ \\
\hline 35 & 134 & Suzume shirazu & 73 & 253 & Ine mochi & 111 & 330 & (330) & 149 & 422 & Bonança** \\
\hline 36 & 136 & Yamato nishiki & 74 & 256 & Shizuoka & 112 & 331 & Rikuu & & & \\
\hline 37 & 139 & Nourin mochi 1 & 75 & 257 & Hiderishirazu & 113 & 335 & Rikuu 23 & & & \\
\hline 38 & 140 & Nourin mochi 17 & 76 & 260 & Kozo & 114 & 336 & Ohata wase & & & \\
\hline
\end{tabular}

Acc. - Accessions; *Different accessions with the same name; **Controls.

color (IC), stigma color (SC), presence and distribution of awn per panicle (PDAP), apiculus and/or awn color (AAC), lemma and palea color (LPC), glumella pubescence (GP), panicle type (PT), threshability (Th), seed coat color (SCC), endosperm type (ET), and grain shape (GS). The quantitative descriptors were: flag leaf length (FLL), flag leaf width (FLW), culm length (CL), culm diameter (CD), number of tillers per plant (NTPP), flowering cycle (FC), maturation cycle (MC), number of panicles per plant (NPP), panicle length (PL), number of spikelets per panicle (NSPP), panicle fertility (PF), ratio between length and width of the grain (RGLW), 1000-grain weight (TGW) and plant production $(\mathrm{PP})$. 
Table 2 - Qualitative descriptors used to evaluate 146 upland rice accessions from Japan and three Brazilian cultivars (controls).

\begin{tabular}{|c|c|c|}
\hline Descriptors & Observed phenotypic classes & Evaluation phase \\
\hline \multicolumn{3}{|l|}{ Qualitative } \\
\hline Leaf color (LC) & 1 - light green; 2 - green; 3 - dark green; 4 - purple. & Early flowering \\
\hline Leaf pubescence (LP) & 1 - glabrous; 2 - intermediate; 3 - pubescent. & Early flowering \\
\hline Lodging resistance (LR) & 1 - absent; 2 - plants with moderate lodging; 3 - plants strongly lodged. & After maturation \\
\hline Internode color (IC) & 1 - green; 2 - gilded; 3 - purple; 4 - purple stripes. & Grain filling \\
\hline Stigma color (SC) & 1 - white; 2 - light green; 3 - yellow; 4 - purple. & Flowering \\
\hline $\begin{array}{l}\text { Presence/distribution of awn } \\
\text { per panicle (PDAP) }\end{array}$ & 1 - absent; 2 - awns on panicle extremity; 3 - awns throughout the panicle. & After grain filling \\
\hline $\begin{array}{l}\text { Apiculus and/or awn color } \\
\text { (AAC) }\end{array}$ & 1 - straw color; 2 - gilded; 3 - red; 4 - purple; 5 - brown; 6 - green; 7 - black. & After grain filling \\
\hline Lemma and palea color (LPC) & $\begin{array}{l}1 \text { - straw color; } 2 \text { - gilded or with gilded lines; } 3 \text { - straw color with brown stains; } 4 \text { - } \\
\text { brown; } 5 \text { - reddish; } 6 \text { - straw color with purple lines; } 7 \text { - purple; } 8 \text { - black; } 9 \text { - white. }\end{array}$ & Maturation \\
\hline Glumella pubescence (GP) & 1 - absent/very weak; 2 - present. & Flowering \\
\hline Panicle type (PT) & 1 - grouped; 2 - intermediate; 3 - open. & Maturation \\
\hline Threshability (Th) & $\begin{array}{l}1 \text { - difficult (less than } 25 \% \text { of the grains were removed); } 2 \text { - intermediate (from } \\
25 \% \text { to } 50 \% \text { of the grains were removed); } 3 \text { - easy (more than } 50 \% \text { of the } \\
\text { grains were removed). }\end{array}$ & After maturation \\
\hline Seed coat color (SCC) & 1 - white; 2 - light brown; 3 - brown; 4 - red; 5 - purple. & After maturation \\
\hline Endosperm type (ET) & 1 - non-glutinous; 2 - intermediate; 3 - glutinous. & After maturation \\
\hline Grain shape (GS) & $\begin{array}{l}1 \text { - round (length/width ratio was less than } 1.50) ; 2 \text { - semi-round (ratio ranged from } \\
1.50 \text { to } 2.00) ; 3 \text { - semi-elongated (ratio from } 2.01 \text { to } 2.75 \text { ); } 4 \text { - elongated (ratio from } \\
2.76 \text { to } 3.50 \text { ); } 5 \text { - very elongated (ratio larger than } 3.50 \text { ). }\end{array}$ & After maturation \\
\hline
\end{tabular}

Table 3 - Quantitative descriptors used to evaluate 146 upland rice accessions from Japan and three Brazilian cultivars (controls).

\begin{tabular}{|c|c|c|}
\hline Descriptors & Observed phenotypic classes & Evaluation phase \\
\hline \multicolumn{3}{|l|}{ Quantitative } \\
\hline Flag leaf length (FLL) & Arithmetic means of the six random samples. & Anthesis \\
\hline Flag leaf width (FLW) & Arithmetic means of the six random samples. & Anthesis \\
\hline Culm length (CL) & Arithmetic means of the six random samples. & Grain filling \\
\hline Culm diameter $(\mathrm{CD})$ & Arithmetic means of the six random samples. & Grain filling \\
\hline Number of tillers per plant (NTPP) & Arithmetic means of the six samples. & Grain filling \\
\hline Flowering cycle (FC) & $\begin{array}{l}\text { Number of days from plant germination until } 50 \% \text { of the } \\
\text { plants in each plot flowered. }\end{array}$ & After flowering \\
\hline Maturation cycle (MC) & Number of days until $50 \%$ of the panicles were mature. & After maturation \\
\hline Number of panicles per plant (NPP) & Arithmetic means of the six samples. & After maturation \\
\hline Panicle length (PL) & Arithmetic means of the six random samples. & After maturation \\
\hline Number of spikelets per panicle (NSPP) & Arithmetic means of the six random samples. & Maturation \\
\hline Panicle fertility (PF) & Arithmetic means of the six ramdom samples. & After maturation \\
\hline $\begin{array}{l}\text { Ratio between length and width of the grain } \\
\text { (RGLW) }\end{array}$ & Arithmetic means of the six random samples. & After maturation \\
\hline 1000 -grain weight (TGW) & Arithmetic means of the six random samples. & After maturation \\
\hline Production per plant (PP) & Arithmetic means of the six random samples. & After maturation \\
\hline
\end{tabular}

For the quantitative characters the statistical analyses were performed using the $\mathrm{F}$ test and in order to group the accessions, the Scott and Knott (1974) test was used. Statistical significance was set at $5 \%(p<0.05)$ and the GENES software was used for all tests (Cruz, 2006). The software PAST (Hammer et al., 2001) was used for the cluster and principal component analyses. Qualitative and quantitative traits data were analyzed separately.
The qualitative traits were transformed into binary data considering the presence or absence $(1 / 0)$ of each character state. The Jaccard similarity coefficient was estimated for qualitative traits, while Euclidean distances were obtained for the quantitative traits. UPGMA (Unweighted pair group method with arithmetic mean) was the clustering method used for both qualitative and quantitative data. 


\section{Results and Discussion}

Polymorphism was found in 12 of the 14 qualitative traits studied; the non-polymorphic traits were the internode color (light green) and panicle type (intermediate). Panicle type (PT) is generally affected by water deficiency before flowering, because this condition changes the angle of the panicle branches and the density of the grains (Bonow et al., 2007). Internode color (IC) often shows variation on color tonality depending on the age of the plants and the soil fertility conditions. Plants usually present a dark green tonality on high soil fertility and a light green one on low soil fertility (Fonseca et al., 2002), which agrees with the soil type used in this study, a franc-clay and low fertility one.

For the traits stigma color (SC) and glumella pubescence (GP), two alternative forms or types were observed. White (65 $\%$ ) and purple (35\%) genotypes were observed for SC, while presence $(76 \%)$ and absence $(24 \%)$ of the pubescence were found in GP. Veasey et al. (2008) reported variation within and among populations of 0 . glumaepatula for stigma color, with three populations $100 \%$ white, four populations $100 \%$ purple, and the others with varying degrees for each color, while white was the only color found on the other South American wild rice species (O. latifolia, O. grandiglumis and $O$. alta).

The characters showing higher variability were leaf pubescence (74\% pubescent, $20 \%$ glabrous and $6 \%$ intermediate), lodging resistance $(37.5 \%$ absent, $37.5 \%$ few lodged and 25 $\%$ moderate), presence and distribution of awn per panicle (PDAP) (55\% absent, $23 \%$ present only at the end of the panicle and $22 \%$ present on all panicle), threshability (73 \% easy threshability, $21 \%$ intermediate and $6 \%$ difficult), endosperm type (31\% glutinous endosperm, $42 \%$ intermediate and $27 \%$ not glutinous), and grain shape (74\% semi-long, $20 \%$ long, 5 $\%$ tightly long and $1 \%$ semi-rounded grain shape). The grain shape character also showed the highest variation in studies conducted in Pakistan by Siddiqui et al. (2007). Although this character is mentioned as qualitative, its evaluation is carried out as a quantitative trait, according to the grain dimentions. The major variation observed was probably due to polygene action and the influence of environmental causes. In relation to PDAP, while the awn is present its length should be influenced by the soil fertilization and plant density (Fonseca et al., 2002). Studies carried by Bisne and Sarawgi (2008) to characterize 32 aromatic rice accessions of Badshah Bhog group from IGKV, Raipur, Chhattisgarh germplasm, found the highest variation among accessions for the traits leaf blade colour, lemma and palea colour, apiculus colour, and lemma and palea pubescence.

The cluster analysis for the qualitative traits using the Jaccard similarity coefficient classified the accessions into two groups (Figure 1). However, the scatter graph from agro-morphological qualitative traits obtained by principal components showed that the accessions did not form distinct groups, with a wide dispersion among the accessions (Figure 2). The first and second components represented $21.1 \%$ and $11.5 \%$ of total variation observed among accessions, respectively. A total of 18 duplicates were found in the cluster analysis (Figure 1), including the following accessions: 14-125, 5-8, 44-128, 27-28, 25-83, 133-142, 78-144, 51-109-118-138, 61-91, 33-48, 85-104, 110-111-112, 89101-132, 65-77-78-87-120-121-140, 143-145, 8-10-39-49, 7-102 and 88-105. None of these duplicates included accessions with the same genotype name. However, Fukuoka et al. (2006), in

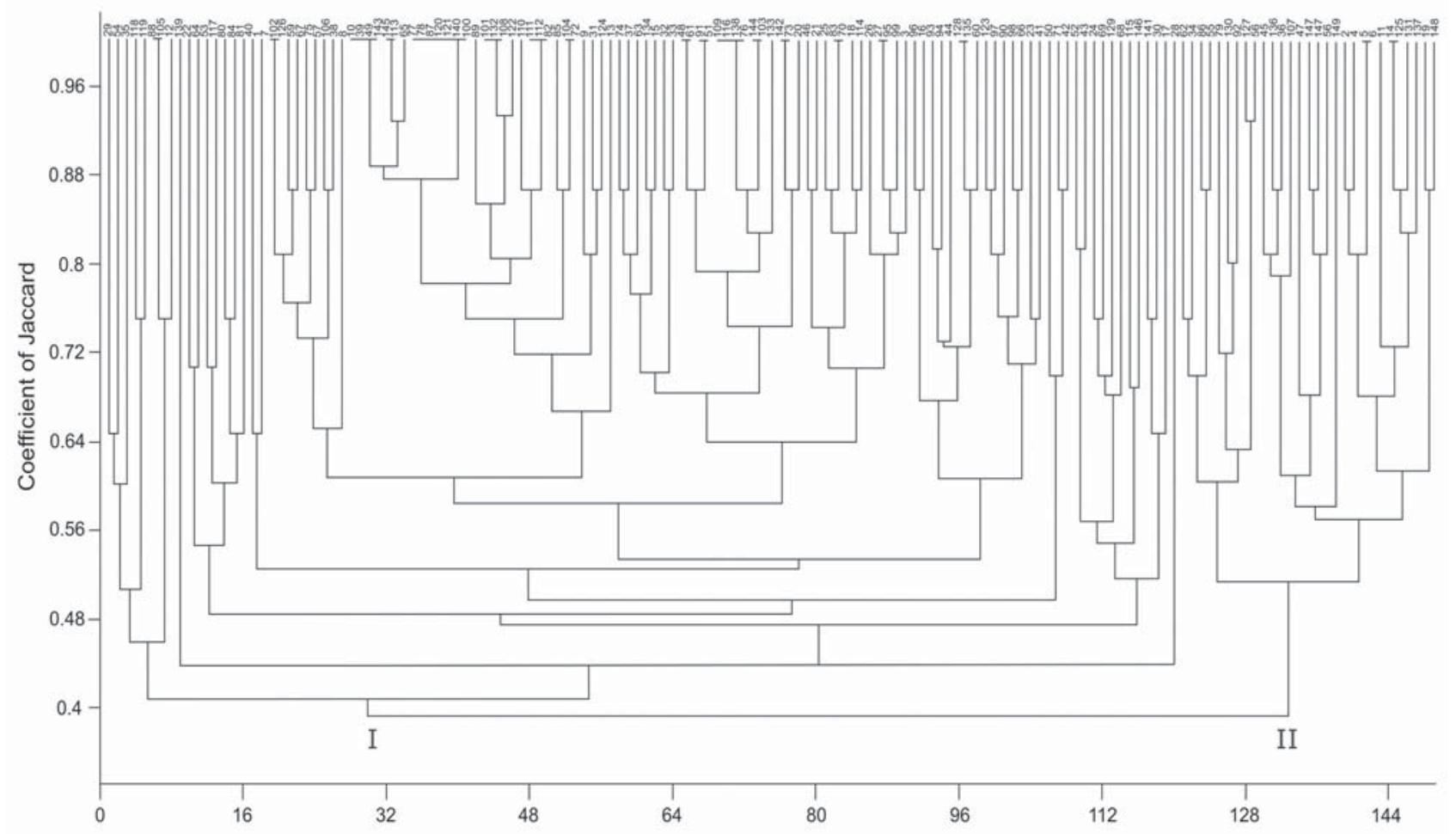

Figure 1 - Dendrogram of similarity patterns by the UPGMA method based on Jaccard similarity coefficient estimated from 14 qualitative agromorphological traits analyzed in 146 accessions of Japanese upland rice and three cultivars (controls) used in the experiment. 


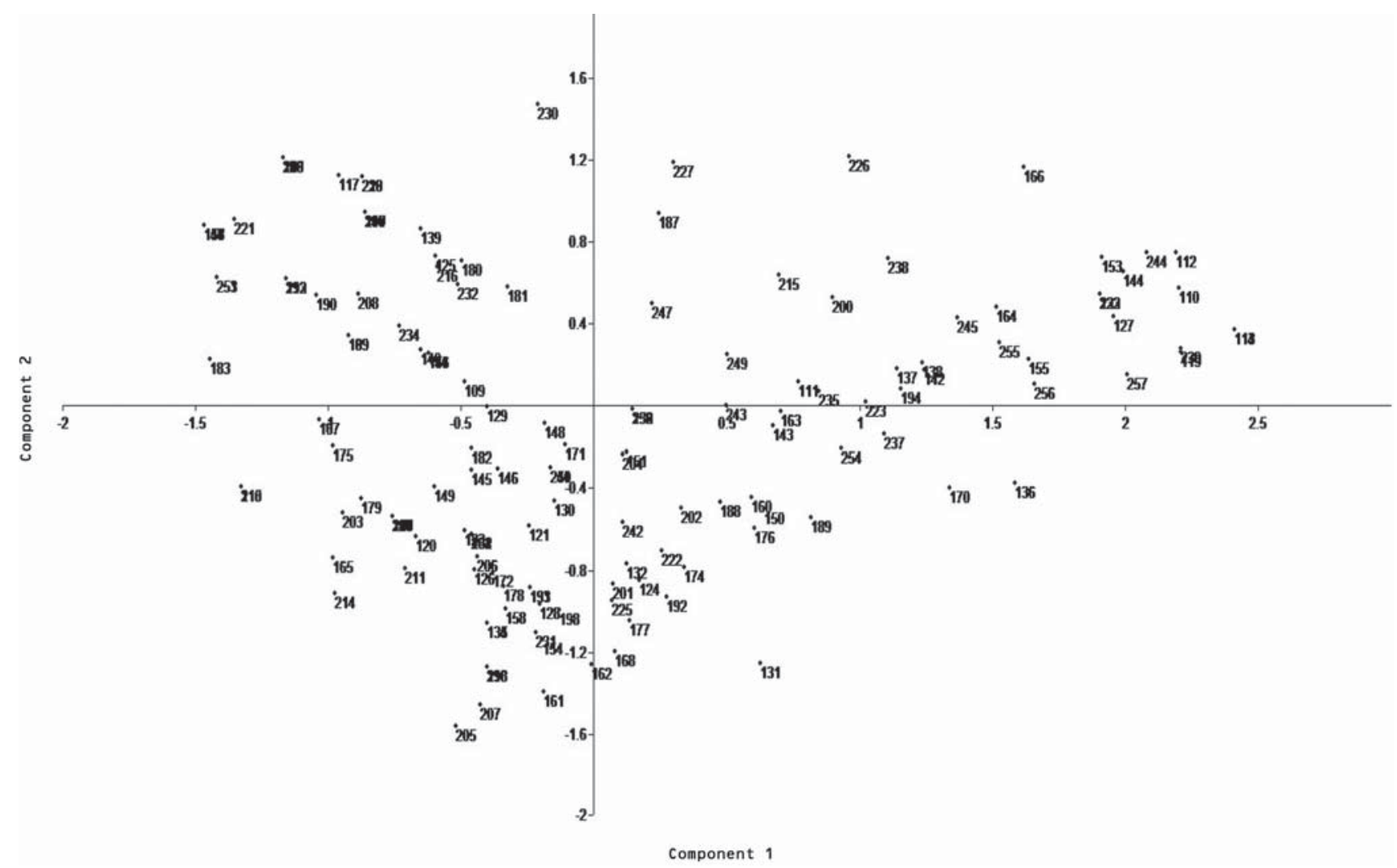

Figure 2 - Scatter graph of 146 accessions of Japanese rice upland germplasm collection of the Universidade Federal Rural de Pernambuco UFRPE and cultivars (controls) used in the experiment from 14 qualitative agro-morphological traits.

Table 4 - Analysis of variance for 14 quantitative traits ${ }^{1}$ for 146 upland rice accessions from Japan and three Brazilian cultivars (controls). Mean squares ${ }^{3}$

\begin{tabular}{lcrrrrrrrrrrrrrrr}
\hline $\begin{array}{l}\text { Sources of } \\
\text { variation }\end{array}$ & DF & FLL & FLW & CL & CD & NTPP & FC & MC & NPP & PL & NSPP & PF & RGLW & TGW & PP \\
\hline Replications & 2 & 11.93 & 0.02 & 297.57 & 0.01 & 6.30 & 13.83 & 92.24 & 2.42 & 0.47 & 74.68 & 5.38 & 0.07 & 25.13 & 71.47 \\
Treatments & 148 & $168.92^{*}$ & $0.30^{\text {ns }}$ & $598.80^{*}$ & $0.04^{\text {ns }}$ & $9.29^{*}$ & $165.81^{*}$ & $11.94 *$ & $6.79 *$ & $19.88^{*}$ & $5590.06^{*}$ & $279.86^{*}$ & $0.50^{\text {ns }}$ & $38.57^{*}$ & $79.38^{*}$ \\
CV $(\%)^{2}$ & & 6.59 & 4.11 & 7.95 & 3.95 & 9.99 & 1.64 & 1.04 & 10.45 & 4.88 & 10.38 & 3.62 & 4.29 & 5.70 & 24.23 \\
Average & & 41.28 & 1.98 & 95.68 & 0.56 & 6.09 & 71.72 & 104.90 & 6.14 & 21.93 & 107.83 & 84.94 & 2.63 & 28.17 & 15.21 \\
\hline
\end{tabular}

${ }^{1}$ FLL-flag leaf length; FLW-flag leaf width; CL-culm length; CD-culm diameter; NTPP-number of tillers per plant; FC-flowering cycle; MCmaturation cycle; NPP-number of panicles per plant; PL-panicle length; NSPP-number of spikelets per panicle; PF-panicle fertility; RGLW-ratio grain length/width; TGW-1000-grain weight; PP-production per plant; DF - degrees of freedom. ${ }^{2} \mathrm{CV}-$ coefficient of variation. ${ }^{3 *}$ Significant at a 0.05 probability level, by $\mathrm{F}$ test.; ${ }^{\text {ns }}$ not significant at a 0.05 probability level, by $\mathrm{F}$ test.

studies with aromatic rice landraces, concluded that significant variation may be found among genotypes with the same name.

Considering the 14 quantitative traits analyzed in this study, differences among accessions $(p<0.05)$ were found for 11 traits (Table 4). The non-significant traits were flag leaf width, culm diameter and the ratio culm/width of the grain. Veasey et al. (2008) also found significant differences and high variability for 11 populations of 0 . glumaepatula, mainly for the characters number of tillers, plant height at flowering, leaf length and width, culm length, days to heading, panicle number, panicle height, flag leaf length, spikelet length and awn length.

The coefficients of variance $(\mathrm{CV} \%)$ showed an optimum experiment precision, with values below $11 \%$ for all characters, except for PPP $(\mathrm{CV}=24.2 \%)$. The analysis performed by Patra and Dhua (2003) had CV values below $27.1 \%$ for all agronomic traits evaluated, except for the character number of panicles, directly related to grain production, showing a CV value of 30.7 .

Results concerning the estimates of variance components among accessions indicate that the variance observed was due to genetic factors, as the values obtained for the $b$ index (CVg/CVe) were above 1 for all characters (Table 5). When the $\mathrm{b}$ index is higher than 1 , there are favorable conditions for selecting superior genotypes considering the predominance of genetic factors rather than environmental factors (Vencovsky and Barriga, 1992). The traits number of spikelets per panicle, culm length, panicle fertility, flowering cycle and flag leaf length 
showed higher genetic variance values, 1821.59, 180.30, 90.13, 54.81 and 53.85, respectively (Table 5). The estimate of the average inheritability among accessions was high, over $82 \%$ for all quantitative traits. The better prediction of the environmental component of phenotypic variance, helps the more realiable estimation of both broad and narrow sense heritability, and so the better planning program for cross and self pollinated plants improvement (Fahliani et al., 2010).

The Scott and Knott (1974) $(p<0.05)$ analysis allowed the formation of several groups among accessions for all characters (not shown data). The flag leaf length character classified the accessions in eight groups. The group with the highest average showed a variation from $58.2 \mathrm{~cm}$ (accession 121) to $64.3 \mathrm{~cm}$ (accession 147), while the group with the lowest average varied from $25.9 \mathrm{~cm}$ (accession 10) to $30.5 \mathrm{~cm}$ (accession 90). Eight groups were obtained for the character flag leaf width, varying from $2.52 \mathrm{~cm}$ (accession 6) to $2.7 \mathrm{~cm}$ (accession 99) for the group with higher scores and from $1.36 \mathrm{~cm}$ (accession 91) to $1.63 \mathrm{~cm}$ (accession 137) for the group with lower scores.

The culm length (CL) trait, related to plant height, classified the accessions in five groups. The higher values varied from $131.1 \mathrm{~cm}$ (accession 137) to $139.3 \mathrm{~cm}$ (accession 125), while the lower values varied from $58.5 \mathrm{~cm}$ (accession 127) to $86.8 \mathrm{~cm}$ (accession 114). The accessions presenting higher means for CL were 125 (369 - without denomination), 148 (IAC 47), 68 (Toga)

Table 5 - Estimates of the variance components, phenotypic and genetic parameters of 14 quantitative traits for 146 upland rice accessions from Japan and three Brazilian cultivars (controls).

\begin{tabular}{lrrrrrr}
\hline \multicolumn{7}{c}{ Phenotypic and genetic parameters } \\
\hline Character $^{1}$ & \multicolumn{1}{c}{$\hat{\sigma}_{\mathrm{f}}^{2}$} & \multicolumn{1}{c}{$\hat{\sigma}_{\mathrm{e}}^{2}$} & \multicolumn{1}{c}{$\hat{\sigma}_{\mathrm{g}}^{2}$} & $h_{m}^{2} \%$ & CVg & Index b \\
\hline FLL & 56.301 & 2.47 & 53.85 & 95.63 & 17.78 & 2.70 \\
FLW & 0.10 & 0.00 & 0.10 & 97.79 & 15.77 & 3.84 \\
CL & 199.60 & 19.30 & 180.30 & 90.33 & 14.03 & 1.77 \\
CD & 0.01 & 0.00 & 0.14 & 98.87 & 21.27 & 5.39 \\
NTPP & 3.10 & 0.12 & 2.97 & 96.01 & 28.31 & 2.83 \\
FC & 55.27 & 0.46 & 54.81 & 99.17 & 10.32 & 6.31 \\
MC & 3.98 & 0.39 & 3.59 & 90.13 & 1.81 & 1.74 \\
NPP & 2.26 & 0.14 & 2.13 & 93.94 & 23.75 & 2.27 \\
PL & 6.63 & 0.38 & 6.25 & 94.25 & 11.40 & 2.34 \\
NSPP & 1863.35 & 41.77 & 1821.59 & 97.76 & 39.58 & 3.81 \\
PF & 93.29 & 3.16 & 90.13 & 96.62 & 11.18 & 3.09 \\
RLWG & 0.17 & 0.00 & 0.16 & 97.45 & 15.30 & 3.57 \\
TGW & 12.86 & 0.86 & 12.00 & 93.33 & 12.30 & 2.16 \\
PP & 23.46 & 4.53 & 21.94 & 82.90 & 30.80 & 1.27 \\
\hline
\end{tabular}

${ }^{1}$ FLL-flag leaf length; FLW-flag leaf width; CL-culm length; CDculm diameter; NTPP-number of tillers per plant; FC-flowering cycle; MC-maturation cycle; NPP-number of panicles per plant; PL-panicle length; NSPP-number of spikelets per panicle; PFpanicle fertility; RLWG-ratio grain length/width; TGW-1000-grain

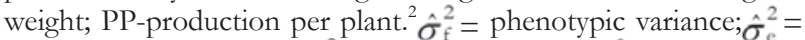
environmental variance; $\hat{\sigma}_{\mathrm{g}}^{2}=$ genetic variance; $h_{m}^{2}(\%)=$ average heritability coefficient; $\mathrm{CVg}=$ coefficient of genetic variance; $\mathrm{CVe}$ $=$ coefficient of experimental variation; Index $\mathrm{b}=\mathrm{CVg} / \mathrm{CVe}$. and 137 (Igisu mochi), with $139.3 \mathrm{~cm}, 132.5 \mathrm{~cm}, 132.2 \mathrm{~cm}$ and $131.1 \mathrm{~cm}$, respectively, all considered of an intermediate height. However, $10.7 \%$ of the accessions [25 (Yonoyuki mochi), 35 (Suzume shirazu), 58 (Taishou mochi), 59 (Kaneko mochi), 60 (Iwate kurumi wase 1), 66 (Miyanishiki), 69 (Col/Miyazaki/1963), 75 (Hiderishirazu), 90 (Furuwase), 100 (Kazusa wase), 103 (Senshou) and 127 (Mogami uruchi 1)] showed CL means below $80 \mathrm{~cm}$, which is why they were considered semi-dwarf plants. The character culm diameter classified the accessions into 14 groups, which shows the high variability among accessions for this trait. The highest value was presented by accession 117 (Tamasari mochi), with $0.97 \mathrm{~cm}$, followed by accessions 123 (Bansei tarou), 5 (Senshou ibaragi 1), 131 (Rikutou), 42 (Minami hata mochi), 14 (Hassaku mochi), 81 (Nourin mochi 6) and 37 (Nourin mochi 1), all with means above $0.8 \mathrm{~cm}$. The group with the lower values showed a variation from $0.38 \mathrm{~cm}$ (accession 79) to $0.42 \mathrm{~cm}$ (accession 108).

Ten groups were obtained for the character number of tillers per plant, with accession 10 (Shiro hige) presenting the highest mean, $14.8 \mathrm{~cm}$, followed by accessions 110 (Gaisen mochi 909), 145 (Shizuoka), 59 (Kaneko mochi), 111 (330-without denomination) and 87 (Urasar), with means above 10 tillers per plant. The accessions that had the lowest means for this trait varied from 3.1 (accession 11) to 4.3 (accession 99). As for the number of panicles per plant, eight groups were obtained, with accessions 140 (Korotou mochi), 110 (Gaisen mochi 909), 59 (Kaneko mochi) and 85 (Arabiya mochi) producing the higher number of panicles, around 10 panicles per plant. The lower means, between 3.1 to 4 panicles per plant, were presented by accessions 133 (Mogami chikanari 1), 131 (Rikutou), 95 (Riku araki), 40 (Col/Fukuti/1965), 82 (Taishou nishiki), 5 (Senshou ibaragi 1), 19 (Oohata mochi) and 83 (Shina mochi). Sarhadi et al. (2009), studying native aromatic rice cultivars from north, east and northeast of Afghanistan, and check cultivars from Japan, Thailand and India, found panicle number per plant ranging from $8 \pm 1.5$ to $13 \pm 1.3$, and observed that this trait was not correlated with grain number per panicle.

The trait panicle length classified the accessions in seven groups. Accessions 147 (IAC 202), 47 (Tomoe mochi), 137 (Igisu mochi), 36 (Yamato nishiki) and 11 (Nakaahara mochi) presented the higher means, $28.7 \mathrm{~cm}, 28.2 \mathrm{~cm}, 27.3 \mathrm{~cm}, 27.0 \mathrm{~cm}$ and $26.8 \mathrm{~cm}$, respectively. Accessions 35 (Suzume shirazu), 48 (Nourin 16) and 100 (Kazusa wase) showed the lower means for this character, $16.5 \mathrm{~cm}, 16.0 \mathrm{~cm}$ and $15.7 \mathrm{~cm}$, respectively.

Plant yield, number of panicles per plant and amount of fertile spicklets are some of the main components of rice production. The trait number of spicklets per plant classified the accessions in ten groups. The accession that showed the highest mean, 302 spicklets, was 81 (Nourin mochi 6), followed by accessions 56 (Ooba kirishima), 147 (IAC 202), 16 (Mie), 47 (Tomoe mochi), 149 (Bonança) and 15 (Mitsukasane), with 267.5, 264.9, 219.2, 218.5, 212.3 and 205.0 spicklets, respectively. The lowest means for this trait showed a variation from 40.4 (accession 58) to 73.9 spicklets (accession 49). Grain number per panicle in Afghan native rice cultivars ranged from 69 to 169 with most Afghan cultivars showing more than 100 grains per panicle (Sarhadi et al., 2009), which is a desirable character for breeding programs. Therefore, the accessions in our study showed much higher values for this trait. 
As for the character panicle fertility, the accessions were classified in eight groups: genotypes Col/Miyazaki/1963 (accession 97), Shiro hige (accession 10), Bansei tarou (accession 123), Kahee (accession 54), Nourin mochi (accession 12) and Oosumi (accession 44) showed the higher means, $97 \%, 96.6 \%, 96.5 \%, 96.5 \%$, $96.2 \%$ and $96.1 \%$, respectively; all of them resulted in fertility values above $90 \%$. Six groups were obtained for the trait 1000 grain weight. The higher means varied from $33.7 \mathrm{~g}$ (accession 86) to $36.2 \mathrm{~g}$ (accession 72), while the lower means varied from $19.5 \mathrm{~g}$ (accession 56) to $21.5 \mathrm{~g}$ (accession 96). This trait ranged from 20 to $32 \mathrm{~g}$ in the Afghan cultivars (Sarhadi et al., 2009).

Finally, character plant production classified the accessions in four groups. The genotypes that presented the higher means for this trait were Oota wase (accession 72), $35.6 \mathrm{~g}$ per plant, Bansei tarou (accession 123), 33.8 g per plant, Jouon (accession 71), $31.1 \mathrm{~g}$ per plant and Nourin mochi 1 (accession 37), $31.0 \mathrm{~g}$ per plant. The group that showed the lower means varied from 4.6 g per plant (accession 35) to $13.0 \mathrm{~g}$ per plant (accession 38). These same traits showed variation among 147 rice accessions in studies conducted by Bajracharya et al. (2006). In studies of ecogeografic and genetic diversity based on morphological characters of indigenous rice in China, Yawen et al. (2003) found wide variations for characters related to production, such as length of the panicle $(10-36 \mathrm{~cm})$ and grain number per panicle (30-340).

Considering the crop development period, the flowering cycle (FC), which is very important in the definition of the maturation cycle (MC) and was the most efficient trait in discriminating the accessions, varied considerably among accessions. It allowed 17 groups to be formed. Accession 53 (Col/
Fukuti/1965) showed the highest mean, a flowering cycle of 95.3 days, followed by accessions 48 (Nourin 16) and 129 (Okka modoshi), 88.3 and 88 days, respectively. Accessions 136 (Wase shinshuu), 76 (Kozo) and 45 (Oohataho), 55 days, and accession 75 (Hiderishirazu), 54 days, showed flowering cycles shorter than the other accessions. Seven groups were obtained for character MC: the longer cycle was presented by genotype Tamasari mochi (accession 117), an average of 115 days, followed by accessions 81 (Nourin mochi 6), 53 (Col/Fukuti/1965), 48 (Nourin 16) and 55 (Hitachi nishiki), 115, 112.7, 112, 112 and 110.7 days, respectively. The genotypes that presented shorter cycles varied from 100.7 days (accession 62) to 103.3 days (accession 133). Variations in the cycle can occur due to season sowing and weather conditions (Fonseca et al., 2002).

In the cluster analysis for the quantitative traits using the Euclidean distance, three groups were formed (Figure 3). One of the groups (group I) classified the accessions 56, 147 and 81 as more divergent than the others, for presenting higher number of panicles, fertile spikelets and plant production, which are important agronomic characters. The analysis of the descriptors used showed that the number of panicles per plant was the most important character in the group classification. The scatter graph considering the quantitative traits showed that accessions 56 (Ooba kirishima), 81 (Nourin mochi 6) and 147 (IAC 202, control), belonging to the most divergent group in the cluster analysis (group I), were also more divergent for the principal component analysis (PCA), followed by accessions 15 (Mitsukasane), 16 (Mie), 47 (Tomoe mochi) and 149 (Bonança, control) (Figure 4), which belong to a subgroup in group 2 of the cluster analy-

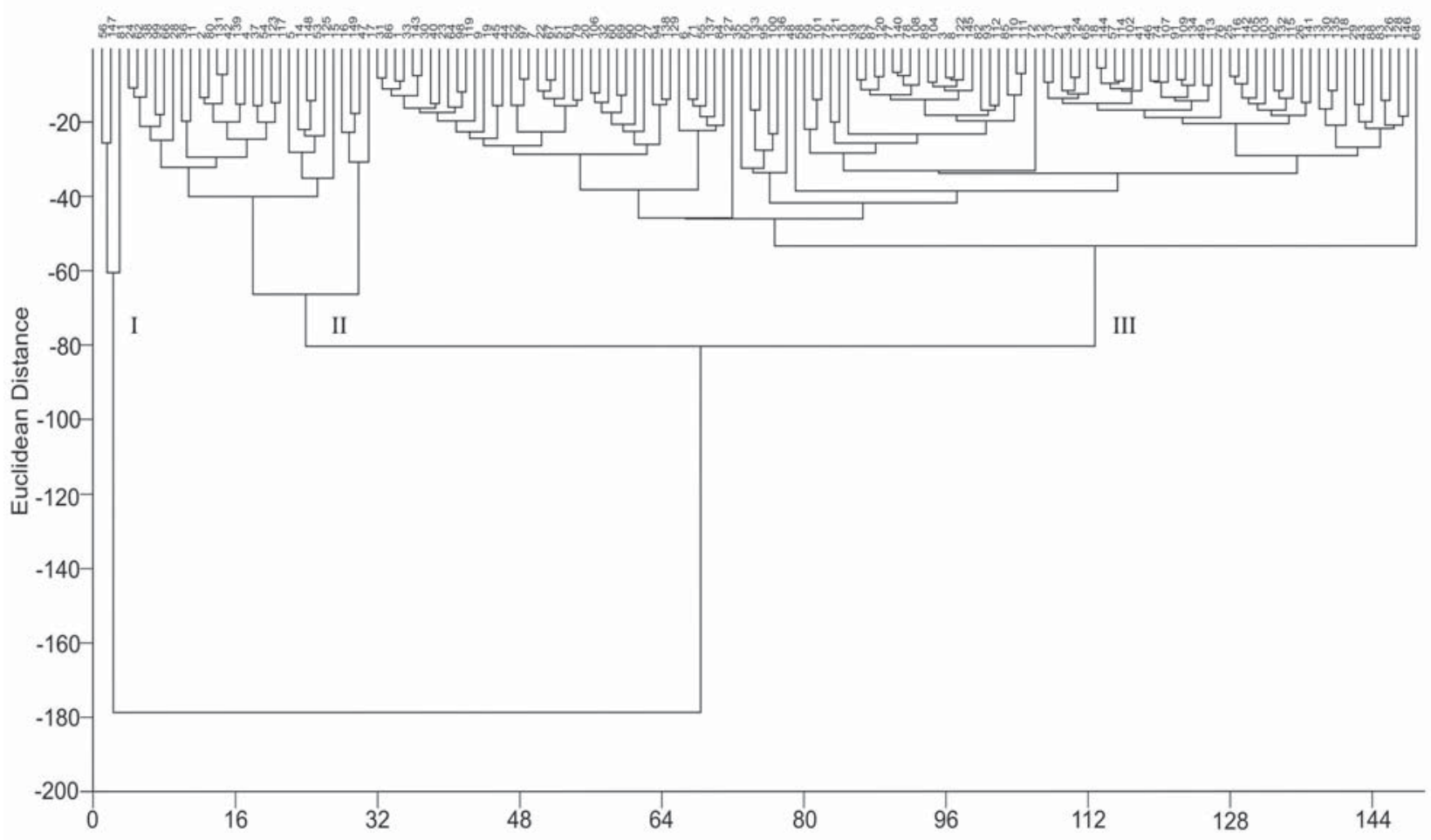

Figure 3 - Dendrogram of similarity patterns by the UPGMA method based on the average Euclidean Distance estimated from 14 quantitative agromorphological traits analysed in 146 accessions of Japanese rice and and cultivars used in the experiment. 


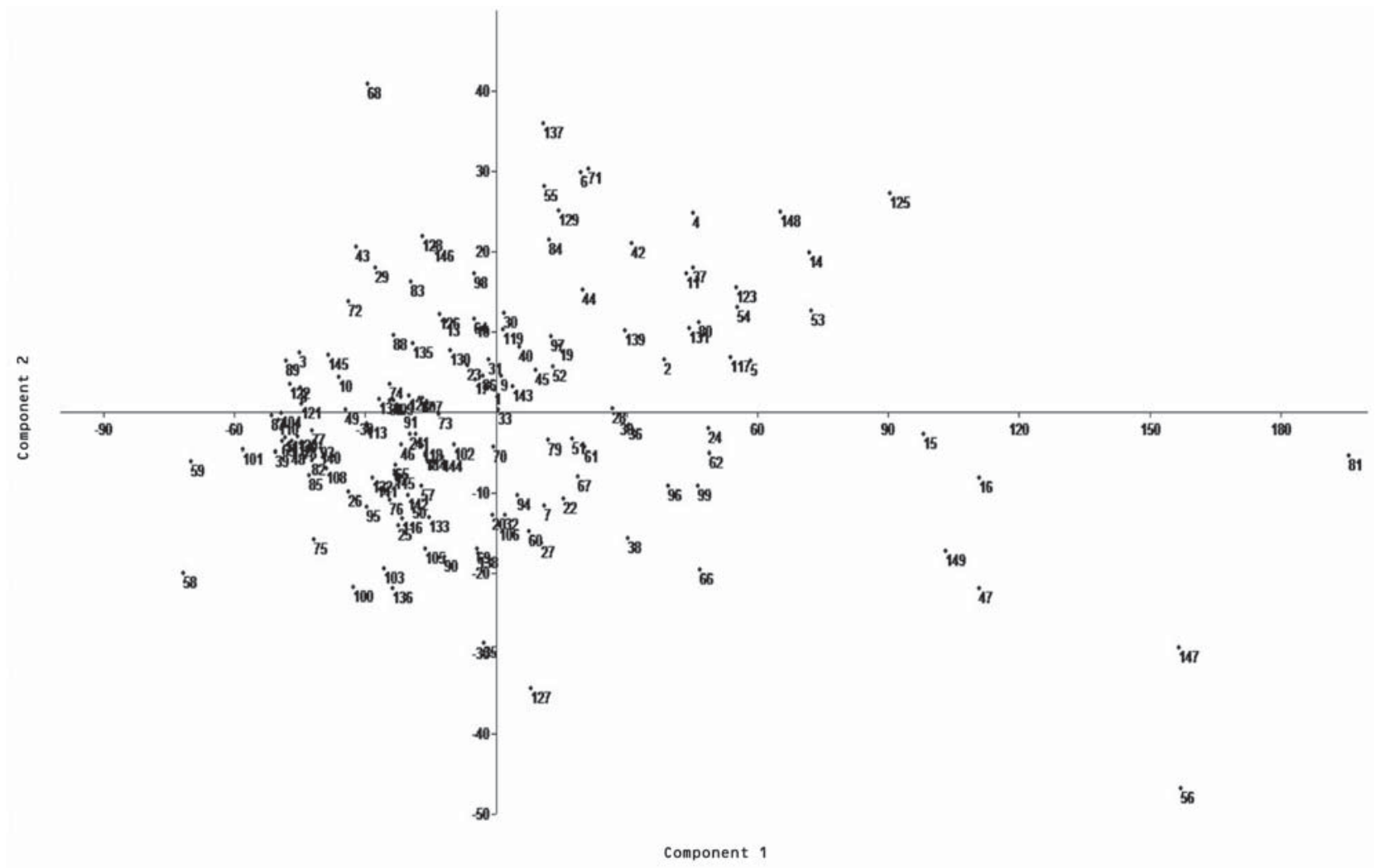

Figure 4 - Scatter graph of 146 accessions of Japanese rice upland germplasm collection of the Universidade Federal Rural de Pernambuco UFRPE and cultivars (controls) used in the experiment from 14 quantitative agro-morphological traits.

sis. These seven accessions had high number of spicklets per plant, while accessions 47 and 147 showed high panicle lengths; accession 147 showed high flag leaf lengths as well. This last accession is the genotype IAC 202, one of the controls used in this study. The first and second components in the PCA represented $83.1 \%$ and $8.4 \%$ of the total variation among accessions. If the initial components accumulate a relatively high percentage of total variation, generally above $80 \%$, they satisfactorily explain the variability among individuals (Madia et al., 1979).

No duplicates were identified among the studied accessions for quantitative traits in the cluster analysis (Figure 3), which means there is a high diversity among the accessions for these traits. Cluster analysis based on agro-morphological diversity assessment in rice was also reported in several studies, such as Ghalain (2006), Naik et al. (2006), Hien et al. (2007), Sarawgi and Bhisne (2007), Mathure et al. (2010), Li et al. (2010) and Zhang et al. (2010). Seetharam et al. (2009) characterized 30 rice genotypes comprising landraces, pure lines, somaclones, breeding lines and varieties by SSR markers and morphological characters. At Euclidian distances the genotypes were grouped into five clusters and the PCA components explained $38.4 \%$ of total variation. Therefore, all data presented in this study allowed the identification of cultivars with distinct morphological traits that could be used as potential parents to facilitate high resolution QTL mapping and validate candidate genes responsible for quantitatively agronomic characters ( $\mathrm{Li}$ et al., 2010).

\section{Acknowledgements}

To Dr. Akihiko Ando and Dr. José Baldin Pinheiro from the Genetics Department of "Luiz de Queiroz" College of Agriculture (ESALQ/USP) for providing the genotypes of Japanese upland rice used in this study.

\section{References}

Bajracharya, J.; Steele, K.A.; Jarvis, D.I.; Sthapit, B.R,; Witcombe, J.R. 2006. Rice landrace diversity in Nepal: variability of agro-morphological traits and SSR markers in landraces from a high-altitude site. Fields Crop Research 95: 327-335.

Bisne, R.; Sarawgi, A.K. 2008. Agro-morphological and quality characterization of Badshah Bhog group from aromatic rice germplasm of Chhattisgarh. Bangladesh Journal of Agricultural Research 33: 479-492.

Bonow, S.; Pinho, E.V.R.V.; Soares, A.A.; Siécola Júnior, S. 2007. Morphological characteristics of rice cultivars application for variety purity certification. Ciência Agrotecnológica 31: 619-627 (in Portuguese, with abstract in English).

Cruz, C.D. 2006. Program Genes: a software in the area of genetics and experimental statistics. UFV, Viçosa, MG, Brazil (in Portuguese).

Fahliani, R.A.; Khodambashi, M.; Houshmand, S. 2010. Estimation of the heritability of agro-morfological traits in rice (Oryza sativa L.) using $\mathrm{F}_{2: 3}$ families. African Journal of Agricultural Research 5: 1297-1303.

Fonseca, J.R.; Cutrim, V.A.; Rangel, P.H.N. 2002. Morpho-Agronomic Descriptors and Phenology of the Lowland Rice Cultivars. Embrapa, Brasília, DF, Brazil (in Portuguese).

Fukuoka, S.; Suu, T.D.; Ebanna, K.; Trinh, L.N. 2006. Diversity in phenotypic profiles in landraces populations of Vietnamese rice: a case study of agronomic characters for conserving crop genetic diversity on farm. Genetic Resources and Crop Evolution 53: 753-761. 
Ghalain, S.S. 2006. Genetic divergence in rice (Oryza sativa L.) genotypes grown in Kamaun Himalaya. Indian Journal of Genetics 66: 37-38.

Hammer, Ø.; Harper, D.A.T.; Ryan, P.D. 2001. PAST: paleontological statistics software package for education and data analysis. Available at: http://palaeo-electronica.org/2001_1/past/issue1_01.htm. [Accessed Aug. 20, 2009]

Hien, N.L.; Sarhadi, W.A.; Hirata, Y.; Oikawa, Y. 2007. Genetic diversity of morphological responses and relationships among Asia aromatic rice (Oryza sativa L.) cultivars. Tropics 16: 343-355.

International Rice Research Institute [IRRD]. 1980. Descriptors for Rice Oryza sativa L. The International Rice Research Institute, Manila, Philippines.

Li, R.; Jiang, T.B.; Xu, C.G.; Li, X.H.; Wang, X.K. 2000. Relationship between morphological and genetic differentiation in rice (Oryza sativa L.). Euphytica 114: 1-8.

Li, X.; Yan, W.; Agrama, H.; Hu, B.; Jia, L.; Jia, M.; Jackson, A. Moldenhauer, K.; McClung, A.; Wu, D. 2010. Genotypic and phenotypic characterization on genetic differentiation and diversity in the USDA rice mini-core collection. Genetica 138: 1221-1230.

Lin, M.S. 1991. Genetic base of japonica rice varieties released in Taiwan. Euphytica 56: 43-46.

Madia, K.V.; Kent, J.T.; Bibby, J.M. 1979. Multivariate Analysis. Academic Press, London, UK.

Mathure, S.; Shaikh, A. Renuka, N. Wakte, K.; Jawali, N.; Thengane, R.; Nadaf, A. 2010. Characterization of aromatic rice (Oryza sativa L.) germplasm and correlation between their agronomic and quality traits. Euphytica DOI: 10.1007/S10681-010-0294-9.

Naik, D.; Sao, A.; Sarawgi, A.K.; Singh, P. 2006. Genetic divergence studies in some indigenous scented rice (Oryza sativa L.) accessions of Central India. Asian Journal of Plant Sciences 2: 197-200.

Patra, B.C.; Dhua, S.R. 2003. Agro-morphological diversity scenario in upland rice germplasm of Jeypore tract. Genetic Resources and Crop Evolution 50: 825-828.

Rosa, M.S.; Santos, P.P.; Veasey, E.A. 2006. Interpopulational agromorphological characterization of Oryza glumaepatula. Bragantia 65: 1-10 (in Portuguese, with abstract in English).

Sarawgi, A.K.; Bisne, R. 2007. Studies on genetic divergence of aromatic rice germplasm for agro-morphological and quality characters. Oryza 44: 74-76.
Sarhadi, W.A.; Ookawa, T.; Yoshihashi, T.; Madadi, A.K.; Yosofzai, W.; Oikawa, Y.; Hirata, Y. 2009. Characterization of aroma and agronomic traits in Afghan native rice cultivars. Plant Production Science 12: 63-69.

Scott, A.J.; Knott, M.A.A. 1974. Cluster analysis method for grouping means in the analysis of variance. Biometrics 30: 507-512.

Seetharam, U.; Thirumeni, S.; Paramasivam, K. 2009. Estimation of genetic diversity in rice (Oryza sativa L.) genotypes using SSR markers and morphological characters. African Journal of Biotechnology 8: 2050-2059.

Siddiqui, S.U.; Kumamaru, T.; Satoh, H. 2007. Pakistan rice genetic resources.I. Grain morphological diversity and its distribution. Pakistan Journal of Botany 39: 841-848.

Veasey, E.A.; Silva, E.F.; Schammass, E.A.; Oliveira, G.C.X.; Ando, A. 2008. Morphoagronomic genetic diversity in American wild rice. Brazilian Archives of Biology Technology 51: 99-108.

Vencovsky, R.; Barriga, P. 1992. Biometrics in plant breeding genetics. Sociedade Brasileira de Genética, Ribeirão Preto, SP, Brazil (in Portuguese).

Villela, O.V.; Furlani Júnior, E. 1996. Seedling age on rice cultivar development. Bragantia 55: 329-339 (in Portuguese, with abstract in English).

Yawen, Z.; Shiquani, S.; Zichao, L.; Zhongyi, Y.; Xiangkun, W.; Hongliang, Z.; Guosong, W. 2003. Ecogeographic and genetic diversity based on morphological characters of indigenous rice (Oryza sativa L.) in Yunnan, China. Genetic Resources and Crop Evolution 50: 567-577.

Yibo, D.; Xinwu, P.; Qianhua, Y.; Hongjin, W.; Xujing, W.; Shirong, J.; Yufa, P. 2010. Ecological, morphological and genetic diversity in Oryza rufipogon Griff (Poaceae) from Hainan Island, China. Genetic Resources and Crop Evolution 57: 915-926.

Zhang, C.H.; Li, J.Z.; Zhu, Z.; Zhang, Y.D.; Zhao, L.; Wang, C.L. 2010. Cluster analysis on japonica rice (Oryza sativa L.) with good eating quality based on SSR markers and phenotypic traits. Rice Science 17: 111-121.

Received October 21, 2010

Accepted March 30, 2011 